\title{
Attribution Theory, Personality Traits, and Gender Differences among EFL Learners
}

\author{
Azar Hosseini Fatemi* \& Arezoo Asghari** \\ *English Department, Ferdowsi University of Mashhad \\ PO box 9177948974, Park Square, Ferdowsi University, Mashhad, Iran \\ E-mail:azar.h.fatemi@ferdowsi.ac.ir \\ **Correspondence: English Department, Ferdowsi University of Mashhad \\ PO box 9177948974, Park Square, Ferdowsi University, Mashhad, Iran \\ E-mail:arezoo.asghari@yahoo.com
}

Received: February 28, 2012 Accepted: April 20, 2012 Published: June 17, 2012

doi:10.5296/ije.v4i2.1455 URL: http://dx.doi.org/10.5296/ije.v4i2.1455

\begin{abstract}
This study was designed to determine whether there is any association between learners' personality traits and their sets of attributions in learning English as a foreign language, regarding their gender differences. To this aim, 216 lower intermediate English language learners, 111 male and 105 female, studying in Shokouh English language institutes in Mashhad took part in the study. They completed NEO-Five Factor Inventory (NEO-FFI) and Attribution questionnaire (ATFLL). The results of the correlational study in male and female groups indicated significant relationships between some of personality traits and sub-scales of attribution theory. The result of t-test showed that the difference between means was not significant in any of the attribution sub-constructs between male and female learners. Regarding personality factors, results showed that the difference between the means was significant only for Agreeableness and Conscientiousness.
\end{abstract}

Keywords: attribution theory, ATFLL questionnaire, personality, NEO-Five Factor Inventory (NEO-FFI), gender difference 


\section{Introduction}

Attribution theory is the internal and external explanation of what is happening behind our own and other people's behavior. This theory mostly considered as part of psychology, deals with "whys" and "whats" that people try to understand the events, judge and act on them. Most researchers believe that the underlying process of understanding and explaining the world is "universal, pervasive, and predictable", although there are some cultural and personal differences (Manusov \& Spitzberg, 2008, p. 38). Language learners have to deal with these "why" questions very often in the process of learning a new language. According to Dornyei (2005), learners have various perspectives towards these attributions as their individual differences affect their views. Learners' personality traits and gender differences could be effective individual factors which might influence learners' overlooks of their ability or inability in learning. With this regard, Williams and Burden (1997) emphasized that finding out how individuals see themselves and how personal constructs affect the process of learning is of great importance.

Despite the previous researches in the field of attribution theory, there is an apparent need for further study on the factors that can have impact on this theory. It seems that the relationship between learners' personality traits and their attributional factors, regarding their gender differences has not been examined to date. Therefore, based on the gaps in the previous studies and limited numbers of researches in which attribution theory has been under study in the field of language learning, and also the importance of this theory (Dörnyei, 2005), it is needed to investigate what qualities the language learners possess that lead them to attributing to different factors. For this aim, this study attempts to explore the relationship between attribution theory and personality traits among male and female Iranian learners of English language.

\section{Theoretical Background}

\subsection{Attribution Theory}

Heider's 'naive' psychology of the laypeople, which was introduced in his book The Psychology of Interpersonal Relationships, is considered as the origin of attribution theory. He paved the way for some writers and researchers to come up with various aspects of this theory. Bernard Weiner $(1979,1980, \&$ 1986) played an important role in constructing the attribution theory which mostly concerns with the factors people attribute their failures and successes to in education and other domains (Williams \& Burden, 1997). Attribution is "the explanation that people give for their success or failure in achievement settings" (Deboer, 1984, p. 325). There are four sets of attributions for people's successes and failures: ability, effort, luck, and task difficulty. Ability and effort are internal factors as they come from inside the person while luck and task difficulty are external attributional factors. Weiner termed these two notions of internality and externality as locus of causality which is one of the main attribution dimensions. The other aspect is called stability, that is, whether the factor is stable or it may be changed. Later, Weiner introduced a third dimension he called controllability which refers to the elements either within people's control or out of their control (Weiner, 1986). 
The following table shows the four sets of attributions:

Table 1. The Four Main Elements of Attribution

\begin{tabular}{l|c|c|}
\multicolumn{1}{c}{} & \multicolumn{2}{c}{ Locus of Causality } \\
Internal & \multicolumn{1}{c}{ External } \\
\cline { 2 - 3 } Stable & Ability & Task Difficulty \\
Stability & Effort & Luck \\
\cline { 2 - 3 } Unstable & E & \\
\cline { 2 - 3 } & &
\end{tabular}

Adapted From Psychology for Language Teachers: A Social Constructivist Approach, by M. Williams and R. L. Burden, 1997.

In brief, ability is an internal and stable factor and the learner does not have a direct control over it whereas, effort is regarded as an internal and unstable factor and the learner has a lot of control over it. Task difficulty is an external and stable element and beyond the control of the learner while luck is considered as an external and unstable element that learner has little control over it.

People make causal judgments in different situations when an event occurs. These judgments are about why other people behaved or acted in a certain way which has substantial consequences. Mostly these causal judgments, which are often beneficial, are made to protect self-esteem and sense of optimism and to control the future. According to Mynatt and Doherty (2002), judging about good and bad outcomes is not done in the same way. To promote and protect their self-esteem, people attribute to internal factors when they have good outcomes and in case of bad results they make external attributions. However, when people make attributions in different situations, they are not totally self-protective. There are times when they accept the responsibility of their failures. People have a strong tendency to ignore or underestimate the effect of environmental and situational factors on causing the behavior. This tendency is called the fundamental attribution error.

Kelley (1967), another key figure in this area, suggests a model to explain how the person determines causation. He argues that there are three sources of person, entities and circumstances that cause the events. In order to determine which source has caused the event, a person uses three criteria of distinctiveness, consistency, and consensus. Distinctiveness refers to the degree to which the actor performs different behaviors encountering different objects. Kelley explains that consistency is the degree to which the actor shows the same behavior toward an object in different situations. Finally, consensus is defined as the degree to which other actors demonstrate the same behavior with the same object. Low consensus, low distinctiveness, and high consistency result in internal attributions. On the other hand, high consensus, high distinctiveness, and high consistency lead to external or situational attributions (Feshbach, Weiner, \& Bohart, 1996). 
Dweck (1996) believed that children's interpretation of an event or situation can determine whether they might keep following the same goal or might change to other goals. Students enter a situation with values, ideas, implicit theories, and beliefs that make certain goals more achievable than others. Dweck emphasized on the reciprocal effects of goals and attributions. The type of attributions students make plays an essential role in their goal pursuit. The reverse of this relation is also true, that is, the goals students are following influence their attributions.

Attribution theory covers a wide range of areas and its continuing dominance among motivation theories is obvious in the number of publications; although, as Williams and Burden (1997) point out, the main focus of this theory has been on sport psychology and there has been little attempt in the area of language learning. Therefore, there is a considerable need for research in this domain. People with certain abilities and motivations act differently in different areas and they have various types of attributions. Therefore, for each domain a certain questionnaire or scale for measuring this theory has been devised and applied. This study is in the context of foreign language learning, thus the review of previous studies addresses learning and specifically language learning. To name some of these studies, Williams and Burden (1999) conducted a qualitative research to find the underlying factors of learners' attributions, how different individuals construct different factors to attribute their successes and failures to, and the relationship between learners' proficiency and their attributional patterns. They also proposed that attribution for success and failure is affected by individual's age, social interactions, contexts, feelings, and environment. Cortes-Suarez and Sandiford (2008) studied the relationship among learners' attribution, a high risk course and low success rated. Folmer et al. (2008) investigated the developmental changes in children about their understanding of ability and effort in facing a negative result. Postlethwaite and Haggarty (2001) in their paper worked on the factors that made secondary school students want to learn, the reasons that made learning difficult, and the role of teachers in this regard. Williams, Burden, and Al-Baharna (2001) carried out a qualitative research on school children concerning their attributions of success and failure in learning English. They highlighted the important role of attribution in learners' motivation and investigated the function of learners' cultural background such as family influence in their attributional perceptions and the range of attributional factors. Based on the need for a standard questionnaire for discovering English language learners' attributions Pishghadam and Modarresi (2008), following the guidelines provided by Weiner (1986), carried out a research to construct and validate a questionnaire to investigate the factors English language learners attribute their successes and failures to. Pishghadam and Zabihi (2011) conducted their research to investigate the relationship between EFL learners' attributions in foreign language learning and their achievement in language classes. Pishghadam and Motakef (2011) studied attributions of high school students, majoring in different fields, for their success and failure in learning a foreign language. Ushioda (1996, 1998, \& 2001) conducted a longitudinal research she found out that two patterns of attribution constructed the positive motivation of learners in the process of learning. The first pattern was attribution of success in second language learning to personal ability and internal factors and the second one was attribution of failure in second language learning to unstable factors that could be overcome. Takahashi 
(2003) investigated the relationship between reading proficiency level of university students and their attribution. Wu (2011) studied attributional preferences of English learning among students studying in non-English majors. Lim (2007) conducted a research on the effects of attributions and task values on foreign language use anxiety.

\subsection{Personality}

Psychologists and personality theorists have attempted to define the term personality, but they lack agreement as they have different individual perspectives. While some have defined this global concept from a comprehensive point of view, others have restricted themselves to a few aspects of personality, and all have their own view of it (Feist \& Feist, 2002). Mayer (2005) argued that personality is an organized system within the individual, which is developing. This system represents the collective action of individual's cognitive, emotional, motivational, social-planning, and some other psychological subsystems.

There are three main approaches to personality, the first of which is the biological approach to explain individual differences in personality. This approach could be considered from three angles: genetics, brain functioning, and evolution. Behavioral genetic emphasized on the genetic influences, specific genes and their mode of action. Neurobiology focused on brain pathways, neurotransmitters and neurobehavioral systems as the major source of differences in personality dimensions. Evolutionary approaches, on the other hand, tried to find the reason for the existence of personality variations and behavioral differences in human beings. Biological studies have illuminated the role of environmental factors. The second approach to personality is the psychoanalytic theory which focuses on social and psychological phenomena and studies the underlying dynamics of human personality. Cognitive approach to personality covers cognitive concepts and mental processes such as personal constructs, explanatory styles, self-conceptions, coping strategies, and emotional intelligence. The focus of this approach is on how people make sense of themselves, their world and their acting within it (Haslam, 2007).

There are many psychologists who believed that personality could be best understood by means of examining people's traits as they argue that there are some characteristics of the individual which stay consistent over time and in different situations. Therefore, their focus is on the organization of traits. In order to study the traits within an individual, many methods have been suggested (Feshbach, Weiner, \& Bohart, 1996). The results of these attempts were a variety of techniques for assessing personality. Interviews have been a popular means of assessing personality because they collect critical information about an individual's personality (Boyle \& Barton, 2008); however, they are sometimes too time-consuming, invalid, and unreliable (Haslam, 2007). Inventories or questionnaires, also known as scales, are the most common techniques which consist of printed statements with fixed set of response options on paper or computer. These inventories are easy to develop, administer, and score (Boyle \& Barton, 2008). Another method is projective test whose purpose is to avoid the limitation of self-report inventories by an open-ended way of responding to ambiguous stimuli such as visual stimuli or verbal instructions (Haslam, 2007). 
Despite all the attempts, psychologists have not been able to answer so many questions regarding personality. Nevertheless, much has been found through scientific and empirical approaches for evaluating and assessing personality (Feshbach, Weiner, \& Bohart, 1996). One of the well-known works for finding the basic elements of personality is Eysenck's (1959). He developed a personality test based on three factors (Feshbach, Weiner, \& Bohart, 1996). Cattell (1965), with a similar view to personality, developed a test based on sixteen factors (Cattell \& Mead, 2008). It was in the late 1980s that psychologists and researchers came to this point that in order to have a better understanding of the domain of personality, they ought to use a common language. They realized that these apparent differences among personality models, which have suggested many personality tests and various trait names, were actually similar. Many psychologists reached the agreement that personality could be described by a five-factor model which was referred to as the "Big Five". This model demonstrates five global factors each of which consists of more specific traits. This model makes it easier to understand and predict individual's behavior (Mynatt \& Doherty, 2002). This model is based on adjectives which describe the personality of an individual. The following is the five components of the Big Five which are referred to as primary traits and the specific traits of each broad factor (Dörnyei, 2005).

Table 2. Components of Big Five Model

Five Main Domains

Openness to Experience

Conscientiousness

Extraversion-Introversion

Agreeableness

Neuroticism-Emotional Stability
Lower Level Facets

Fantasy, aesthetics, feelings, actions, ideas, and values

Competence, order, dutifulness, achievement striving, self-discipline, and deliberation

Warmth, gregariousness, assertiveness, activity, excitement-seeking, and positive emotions

Trust, straightforwardness, altruism, compliance, modesty, and tender-mindedness

Anxiety, angry hostility, depression, self-consciousness, impulsiveness, and vulnerability

Adapted from The Psychology of the Language Learner Individual Differences in Second Language Acquisition, Z. Dörnyei, 2005.

Personality characteristics and their relationships to success in different activities and tasks have been an interesting area under study in the past half century (Brown, 2007). In this domain, many researchers have studied the relationship between the Big Five Personality Factor Theory and different variables such as personality traits, human resources, risk-taking, psychopathology, cultural diversity, age, gender, and academic achievement (Karamana, Dogana, \& Cobana, 2010). Due to the vast numbers of the researches in this domain, the present study is limited to some papers and studies relating to Big Five Model as its main concern. 
Busato, Prins, Elshout, and Hamaker (1999) did a research on the relationship among learning styles, the Big Five personality traits, and achievement motivation. Müller, Palekčić, Beck, and Wanninger (2006) based their study on the differential psychology models of the Big Five model and self-determination theory to investigate the role of personality, motives for studying, and the learning environment in predicting self-determined learning motivation at university level. Chamorro-Premuzic, Furnham, and Lewis (2007) tried to find the relationship between personality traits and learning approaches, and personality traits and preferences for teaching method. Chen and Zhang (2011) studied the relationship among temperament dimensions, the Big Five personality traits, and achievement goals. Lee and Klein (2002) conducted a research to examine the relationship between Conscientiousness and self-efficacy, Conscientiousness and self-deception, and self-efficacy and learning.

\subsection{Gender}

There are different definitions of gender proposed by scholars and researchers. Among these definitions, Desprez-Bouanchaud, Doolaege, and Ruprecht (1987, p. 20-21) have defined this term as: "The term gender refers to the economic, social, political and cultural attributes and opportunities, associated with being male and female". In the majority of communities, males and females' access to resources is different. They differ in the type of activities they do and the decision-making they participate in. Mostly females have less access to resources, decision-making, and opportunities. Generally there are two views toward gender: "Conservatives" which has a fixed and biologically determined perspective and "progressives" which sees gender as the outcome of historical and cultural effects (Forsthuber, Horvath, Motiejunaite, 2010, p.16).

Attribution theory as the dominant concept of motivation with emphasizing on cognitive perspectives has been utilized to investigate gender differences in achievement motivation (Meece, Glienke, \& Burg, 2006). In other words, gender is one of the factors that can influence achievement in different fields. Sex differences in the area of achievement are rather small and have been decreasing. For example, gender difference is small in science achievement. Girls have advantage in reading. Boys and girls are similar in mathematics during the first years of school, but boys' advantage emerges in the later school years (Forsthuber, Horvath, Motiejunaite, 2010).

Some researchers could not find any significant differences in male and female attributions for their success and failures (e.g., Martin, Kovac \& Hryshko, 1989; Travis, Phillippi \& Henley, 1991). However, research findings of gender differences in causal attribution are not consistent. There are a number of researches that have reported gender differences in causal attributions. Some of them concluded that women attribute their successes to external factors (Feather, 1969; Meehan \& Overton, 1986; Pasquella, Mednick \& Murray, 1981; Viaene, 1979). However, some other researchers found out that women attribute their successes more to effort than ability (Erkut, 1983; Parsons, Meece, Adler \& Kaczala, 1982; LaNoue \& Curtis, 1985). There are some studies that believe men protect their self-esteem better than women because they consider internal factors (lack of ability) less important than women do (Basow \& Medcalf, 1988; D'Amico, Baron \& Sissons, 1995; 
LaNoue \& Curtis, 1985). Some researchers pointed out that these gender differences in attributional patterns vary according to the achievement domain, student ability level, and research methodology (Parsons, Adler, \& Kaczala, 1984; Parsons, Kaczala, \& Meece, 1982).

Beyer (1998 \& 1999) studied gender differences in attributions and emotions for successes and failures on examinations. Males attribute their successes to ability more than females. Females attribute to studying and paying attention. Males ascribed their failures to lack of studying and interest while females attributed to lack of ability. Females' emotions were stronger than males' after experiencing success or failure. Batool, Arif, and Naseer Ud Din's (2010) study investigated gender difference of causal attributions of two groups including mainstream and religious school students and the effect of their attribution on their academic achievement. Peacock (2010) conducted his study trying to investigate the relationship among attribution, proficiency, gender, and academic discipline. In language learning domain, Williams, Burden, Poulet, and Maun (2004) did a research to find out about attributions for success and failure in foreign language learning of secondary students and the effect of gender, age, perceived success, and the specific language that the learners studied. Pishghadam and Modarresi (2008) constructed and validated an attribution questionnaire. The researchers administered the questionnaire to a university population and examined the role of gender and major of the participants in their attributions.

The researches done in the domain of personality traits and gender differences showed that males tend to show higher levels of assertiveness, aggressiveness, and self-esteem but their levels of trust, anxiety, and tender-mindedness is low (Feingold, 1994). Women scored higher than men on Neuroticism and Agreeableness in adults and older ages (Chapman, Duberstein, Serensen, \& Lyness, 2007). Budaev (1999) found that females scored higher on Agreeableness and low Emotional Stability vs. Hostility and high Emotional Stability. Duff, Boyle, Dunleavy, and Ferguson (2004) considered the relationship among students' learning approaches, the Big Five personality factors, age, gender, prior academic performance, and educational achievement. In another study, college students of fifty cultures identified an adult man or woman whom they knew very well to rate their personality types by means of Big Five factors. It was reported that men were higher in assertiveness, excitement seeking, and openness to ideas. Women were rated as being higher in anxiety, vulnerability, aesthetics, feelings, and tender-mindedness (McCrae, Terracciano, \& 78 Members of the Personality Profiles of Cultures Project, 2005). Costa, Terracciano, and McCrae (2001) did a research in twenty six cultures. They found out that gender difference in personality traits of college-age students and adults are rather small. They reported that women are higher in Neuroticism, Agreeableness, Warmth, and Openness to feelings while men scored higher in assertiveness and openness to ideas.

It could be stated at this point that personality factors have been applied to the learning domain and second and foreign language learning. However, to the best knowledge of the researchers, no studies have investigated the probable effect of male and female learners' personality traits on their successes and failures and the factors to which they ascribe their failing or succeeding in language learning. In case learners' personality types and their gender differences have influence on their attributions, this fact can give more awareness to language 
teachers about learners' individual differences in viewing their successes or failures. It can also encourage or discourage more perseverance, and consequently affect students' motivation for learning.

\section{Research Questions}

Type of attributional factors can determine learners' future successes or failures. Moreover, investigating the effect of personal constructs upon the process of learning a new language has been one of the main concerns of researchers. And as gender difference is one of the factors that can have effect on students' achievements; therefore, this study aimed at seeking the relationship between language learners' personality traits and their attribtional factors and the effect of gender differences on these two groups of factors. Therefore, this study was set out to answer the three following questions:

Q1: Is there any significant relationship between male EFL learners' attributions and their personality traits?

Q2: Is there any significant relationship between female EFL learners' attributions and their personality traits?

Q3: Is there a significant difference between the means of male and female groups, regarding the Big Five personality traits and attributional factors?

\section{Method}

\subsection{Participants}

The total population participating in this study included two hundred and sixteen English language learners, 111 were male and 105 female. All were Iranian EFL learners studying at Shokouh Language Institute, a private language institute in Mashhad, Iran. For this study, lower intermediate students (as they were classified by the authorities of the institute) were chosen as they had several years of experience in learning English and enough knowledge of this language to give their views on the factors that cause their successes or failures in their learning process. To control the age of learners, the students within the range of 12 to 17 were selected. This age range was chosen because it is the critical period that learners might develop wrong attributions, which could lead to hindrance in learning. As this study was focusing on the investigation of the probable differences between male and female participants regarding their personality traits and their attributions for successes and failures, we attempted to make an acceptable balance while selecting the classes to take the questionnaires.

\subsection{Instruments}

For eliciting data two instruments were used: NEO-Five Factor Inventory and ATFLL Questionnaire.

\subsubsection{ATFLL Questionnaire}

ATFLL Questionnaire was used to check learners' attributional factors. This 
questionnaire is the only validated instrument designed to investigate the factors to which the learners attribute their successes and failures in the process of learning English as a foreign language. It was constructed and developed by Pishghadam and Modarresi (2008). In ATFLL questionnaire the four factors of ability, effort, luck, and task difficulty, which Weiner (1979) had suggested as the sets of attribution, were given new labels of Emotions, Self-image, Intrinsic Motivation, and Language Policy. Emotions as the first attributional factor is checked through 9 items, the second factor through 11 items, the third factor through 6 items, and the fourth factor through 4 items. The overall number of items is 30 and the questionnaire is in the 5-point Likert-type scale with "strongly agree" at one end and "strongly disagree" at the other. The questionnaire was written in Persian language. The reported reliability was 0.84 and in this study the reliability of the whole items (i.e. 30 items) estimated by Cronbach Alpha was 0.80 .

\subsubsection{NEO-Five Factor Inventory (NEO-FFI)}

NEO-Five Factor Inventory (NEO-FFI) was used to find out about the personality traits of learners in this study. According to Cano-Garcia, Padilla-Munoz, and Carrasco-Ortiz (2005) "the personality inventory NEO-FFI is the reduced version of the NEO-PI-R, one of the most frequently used instruments in the evaluation of Big Five Factors, these being basic elements of personality structure" (p. 932). The overall number of questions in this instrument is 60. The items are scored according to a Likert-type scale of five points, ranging from strongly agree to strongly disagree (McCrae \& Costa, 2008). There are 12 items per domain in the form of statements. Some of these statements are designed in the first person for self-report and others are in the third person for observing rating. The Persian adaptation of the NEO-Five Factor Inventory was utilized in this study. Garousi, Mehryar and Ghazi Tabatabayi (2001) examined the reliability and validity of this 60-item inventory in Iran. Cronbach's $\alpha$ coefficient was used to examine the reliability of this inventory and the reported alpha was between 0.56 and 0.87 . The reliability of NEO-Five Factor Inventory with 60 items as was checked in this study was equal to 0.74 .

\subsection{Procedure}

The data were collected in August, 2011. Two questionnaires of NEO-Five Factor Inventory (1992) and ATFLL questionnaire (2008) were administered to the population. Two hundred and sixteen language learners, who were homogenized by the institute as they were studying at certain levels in Shokouh English Language Institutes in Mashhad, filled out both questionnaires. NEO-FFI consists of 60 items and the attribution questionnaire has 30 questions. Both questionnaires were administered in one session. It took about 30 to 40 minutes for the respondents to complete the questionnaires.

After the process of data collection, SPSS 16 program was used to analyze the data. First, the researchers measured the reliability of both questionnaires. Then the Pearson product moment formula was used to calculate the correlation between learners' personality traits and attributional factors considering their gender differences. Finally, t-test was run to see whether the difference between the means of male and female groups were significant regarding their types of personality and their attributions. 


\section{Results}

The first question of this study to be dealt with was whether there was a relationship between male learners' personality traits and their attributional factors. Therefore, this relationship was put to test by means of Pearson product moment correlation. The following table shows the result of the correlational analysis.

Table 3. Correlational Analyses/Personality Traits \& Attributional Factors among Male Learners

\begin{tabular}{llllll}
\hline & Neuroticism & Extraversion & $\begin{array}{l}\text { Openness } \\
\text { to } \\
\text { Experience }\end{array}$ & Agreeableness & Conscientiousness \\
\hline Emotions & -.160 & .026 & -.039 & .166 & .172 \\
$\begin{array}{l}\text { Self-image } \\
\text { Intrinsic }\end{array}$ & $-.439^{* *}$ & .163 & .075 & $.436^{* *}$ & $.301^{* *}$ \\
$\begin{array}{l}\text { Motivation } \\
\text { Language }\end{array}$ & -.062 & .093 & .059 & $.213^{*}$ & $.374^{* *}$ \\
$\begin{array}{l}\text { Policy } \\
* \mathrm{p}<.05, * * \mathrm{p}<.01\end{array}$ & .084 & .062 & .075 & .134 \\
\hline
\end{tabular}

As Table 3 demonstrates, Neuroticism correlated negatively with Self-image $(r=-.439$, $\mathrm{p} \leq .05)$. Agreeableness correlated positively with Self-image $(r=.436, p \leq .05)$ and moderately with Intrinsic Motivation $(\mathrm{r}=.213, \mathrm{p} \leq .05)$. There was a correlation between Conscientiousness and Self-image $(r=.301, \mathrm{p} \leq .05)$ and Conscientiousness and Intrinsic Motivation $(\mathrm{r}=.374, \mathrm{p} \leq .05)$. Interestingly, Extraversion and Openness to Experience did not correlate with any of the attributional factors among male learners.

To answer the second research question, Pearson product moment formula was used again to investigate whether there was a relationship between female learners' personality traits and their attributional factors

Table 4. Correlational Analyses/Personality Traits \& Attributional Factors among Female Learners

\begin{tabular}{|c|c|c|c|c|c|}
\hline & Neuroticism & Extraversion & $\begin{array}{l}\text { Openness } \\
\text { to } \\
\text { Experience }\end{array}$ & Agreeableness & Conscientiousness \\
\hline Emotions & -.114 & $.250^{* *}$ & .068 & .176 & .161 \\
\hline Self-image & $-.386^{\star \star}$ & $.331^{\star \star}$ & .148 & $.271^{\star \star}$ & $.379^{\star \star}$ \\
\hline $\begin{array}{l}\text { Intrinsic } \\
\text { Motivation }\end{array}$ & -.145 & $.336^{* *}$ & -.013 & $.265^{* *}$ & $.379^{* *}$ \\
\hline $\begin{array}{l}\text { Language } \\
\text { Policy }\end{array}$ & -.017 & .084 & .062 & .075 & .134 \\
\hline
\end{tabular}


$* \mathrm{p}<.05, * * \mathrm{p}<.01$

Table 4 shows that Neuroticism correlated negatively with Self-image $(r=-.386, p$ $\leq .05)$. There was a correlation between Extraversion and Emotions $(\mathrm{r}=.250, \mathrm{p} \leq .05)$, Extraversion and Self-image $(\mathrm{r}=.331, \mathrm{p} \leq .05)$, and Extraversion and Intrinsic Motivation $(\mathrm{r}$ $=.336, \mathrm{p} \leq .05)$. Openness to Experience correlated with none of attributional factors, like male learners. Agreeableness correlated with Self-image $(r=.271, \mathrm{p} \leq .05)$ and also with Intrinsic Motivation $(\mathrm{r}=.265, \mathrm{p} \leq .05)$. There was a positive correlation between Conscientiousness and Self-image $(r=.379, \mathrm{p} \leq .05)$ and Conscientiousness and Intrinsic Motivation $(\mathrm{r}=.379, \mathrm{p} \leq .05)$.

Gender differences in EFL learners attributional factors and personality traits was examined by independent sample t-test.

Table 5. Independent Samples t-test/Gender, Attribution Factors and Five Factor Personality Groups

\begin{tabular}{lllll}
\hline & \multicolumn{2}{l}{ Male $(\mathrm{N}=111)$} & \multicolumn{2}{l}{ Female $(\mathrm{N}=105)$} \\
& Mean & Mean & $\mathrm{t}$ & Sig. (2-tailed) \\
\hline Emotions & 31.35 & 31.89 & -.669 & .504 \\
Self-image & 44.51 & 44.76 & -.279 & .780 \\
Intrinsic Motivation & 23.63 & 23.70 & -.225 & .822 \\
Language Policy & 12.23 & 12.19 & .100 & .920 \\
Neuroticism & 32.37 & 33.81 & -1.474 & .142 \\
Extraversion & 42.59 & 43.33 & -1.069 & .286 \\
Openness to & 39.60 & 40.61 & -1.328 & .186 \\
Experience & & 44.61 & -3.178 & .002 \\
Agreeableness & 42.20 & 47.05 & -2.558 & .011 \\
Conscientiousness & 44.32 & &
\end{tabular}

As Table 5 demonstrates, the difference between the means is not significant in any of the attribution sub-constructs. Regarding personality factors, results show that the difference between the means is significant only for Agreeableness $(t=-3.178, p \leq .05)$ and Conscientiousness $(\mathrm{t}=-2.558, \mathrm{p} \leq .05)$.

\section{Discussion}

The aims of the present study were first to investigate the relationship between male EFL learners' attributions and their personality traits, second to see if there was a significant relationship between female EFL learners' attributions and their personality traits, and finally to see if there is a significant difference between the means of male and female groups, regarding the Big Five personality traits and attributional factors.

Regarding the first goal, the results of the correlational study showed that Neuroticism correlated negatively with Self-image among male EFL learners. Neurotic people are not stable in their emotions and have more negative emotions (Watson, Clark \& Harkness, 1994). 
The results of so many studies showed that Neurotic people could be very disagreeable in work and study (Barrack \& Mount, 1993; De Fruyt \& Mervielde, 1996; Zhang, 2003; Chamorro-Premuzic, Furnham \& Lewis, 2007). Zhang (2003) and Chamorro-Premuzic, Furnham, and Lewis (2007) conducted researches which showed that neurotic students resorted to surface learning approach rather than deep and achieving approaches; therefore, they obtained poor grades in school. These students were externally motivated and Neuroticism caused them to learn the minimum requirements to pass their courses. Learners with low scores in Neuroticism are emotionally stable; therefore, they are calm, relaxed, comfortable, and content. Those learners who were emotionally stable had more positive emotions and they had more positive feelings of personal control. As a result, they are attributing to Self-image. The correlation between Agreeableness and two factors of Self-image and Intrinsic Motivation was positive. This personality factor primarily deals with interpersonal qualities. Those with high scores are friendly, kind, cooperative, generous, and trusting (Costa \& McCrae, 2006; Dörniye, 2005; Whalen \& Gates, 2007). Therefore, this group of learners experience positive emotions in the process of language learning and they have a positive Self-image. Unlike some studies carried out in academic domains which did not show a relationship between Agreeableness and academic success or motivation (De Fruyt \& Mervielde, 1996; Zhang, 2003), the results of this study confirmed the relationship between this personality factor and the two of attribution factors. Conscientiousness also correlated with Self-image and Intrinsic Motivation. Those who have high scores in Conscientiousness are social, expressive, and often experience positive emotions (Costa \& McCrae, 2006). This group of learners are systematic, efficient, hardworking, responsible, self-disciplined, goal-oriented, and achievement striving. They devote themselves wholly to work and pursue accomplishment and competence (Dorniye, 2005; Costa \& McCrae, 2006; Whalen \& Gates, 2007). This could be the reason why they attribute to their Self-image. These people seem to be quite focused and tend to motivate themselves to continue so they are intrinsically motivated. Surprisingly, none of these four attribution factors correlated with Openness to Experience and Extraversion. People with high scores in Openness to Experience are creative, flexible, imaginative, and untraditional (Costa \& McCrae, 2006; Dörniye, 2005; Whalen \& Gates, 2007). The opportunity to learn is more important for them than grades (Zhang, 2003). Unfortunately, the rigid, fixed, and centralized educational system in Iran is limiting the learners to their books and final exams so it is taking away the opportunity to seek novelty, originality, and creativity.

Regarding the second goal, Neuroticism correlated negatively with Self-image. Moreover, Extraversion related to Emotions, Self-image, and Intrinsic Motivation. The introversion-extraversion dichotomy is the most researched personality dimension in the field of second language learning. According to International Personality Item Pool (IPIP-NEO) "Extraverts enjoy being with other people, are full of energy, and often experience positive emotions" (cited in Whalen \& Gates, 2007, p.85). Therefore, extravert learners, who are experiencing positive emotions attribute to Emotions and Self-image. Some studies suggested that Extraversion has a significant role for experiences of competence and success in classrooms (Mayer, 2006 as cited in Muller, Plekcic, Beck \& Wanninger, 2006; Grant \& Cambre, 1990). Intrinsically motivated learners tend to work to improve their English rather 
than to please teachers by achieving good grades. Therefore, they will have a better chance of future success as they are internally involved and have their own reasons of achieving competence for learning a new language. However, those learners who are extrinsically motivated instead of focusing on the learning activity itself concentrate on something external (Pishghadam \& Modarresi, 2008) which might be omitted during the process of learning. Thus the feeling of pride is not created in the learners as the source of success does not belong to themselves. As it was explained previously, Openness to experience did not correlate with any of attributional factors among male EFL learners. Likewise this personality trait did not have any significant relationship with the four attributional factors among female participants. Two other personality factors of Agreeableness and Conscientiousness among females correlated with Self-image and Intrinsic Motivation as they did in male EFL learners following the same line of reasoning.

Regarding the difference between male and female learners concerning their attributions for success and failure and their personality factors, t-test was run. The results showed that the difference between means of these two groups was not significant in any of the attribution sub-constructs in this study. These results confirmed some other researchers (e.g., Martin, Kovac \& Hryshko, 1989; Travis, Phillippi \& Henley, 1991; Wu, 2011) ideas about lack of gender differences between male and female students in their attributions for their success and failures in learning English as a foreign language. According to Hyde (2005), men and women are quite similar in most psychological variables. However, the results of the present study were not in line with the study done by some other researchers (e.g. Pishghadam \& Modaressi, 2008; Pasquella, Mednick \& Murray, 1981; LaNoue \& Curtis, 1985; D'Amico, Baron, \& Sissons, 1995) who pointed to the fact that males and females attribute differently. This could be due to cultural, social, and age differences. As Arnot, David, and Weiner (1999, p. 57) believe "the pattern of sex differences is often unstable across cultures, across time within cultures, and also through time in the development of children".

Concerning personality factors, results showed that the difference between means is significant only for Agreeableness and Conscientiousness in 216 participants. According to Feingold (1994), gender differences in personality traits were generally constant and robust across different ages, educational levels, and cultures. For instance, Schmitt, Realo, Voracek, and Allik (2008) carried out a research in fifty five cultures. They found out that women had higher scores in Neuroticism, Extraversion, Agreeableness, and Conscientiousness. They believed that sex differences in personality traits were larger in the nations with higher levels of human development such as long and healthy life, economic wealth, and equal access to knowledge. The main reason for sex difference variation in these different cultures was the changes in men's personality traits. It is worth mentioning that most of the related studies reviewed in the current paper were carried out on college-age students or adults while the subjects of this research were teenagers. According to Costa and McCrae (1989 \& 2002), personality traits change in adulthood. The origins and sources of age changes could be traced in environmental influences common to all cultures or in biologically based intrinsic maturation (Costa \& McCrae, 2006). They reported that Neuroticism and Extraversion decrease, while Agreeableness and Conscientiousness increase with age. Moreover, Openness 
to Experience at first increases and later decreases. Changes happen more in early adulthood than before or after it. They also found that similar developmental patterns are investigated for male and female (McCrae \& Costa, 2003).

The primary implication of this study is raising awareness in language teachers not only in language institutes, but also junior high school, high school, and university. This research was carried out to give this message to language teachers that learners have certain perceptions of their language learning and these beliefs are related to many factors such as individual differences and specifically personality traits and gender differences. If language learners' perception of their successes and failures in the process of learning is wrong, it will have a direct impact on their future attempts. Consciousness raising about this relationship is not limited to teachers, as it is also essential to make learners aware of the attributional factors they ascribe their successes and failures to. Making them sensitive to the factors which cause that type of attribution is also of great importance. One of these related factors can be their type of personality which they are not conscious of. When the learners know that they are attributing to a wrong, stable, and uncontrollable factor due to their type of personality, it would be easier for them to alter their negative attitudes toward learning English. The results of this study can also come in handy for researchers in the process of Attribution Retraining. Learners' subjective explanations of the result and outcome of their learning play an important role when they start planning their future actions. Therefore, in reattribution process the researcher should consider different factors which have control over these inappropriate attributions to raise the chances of more future successes and less repeated failures because of incorrect attitude toward learning. Learners' personality traits could lead to wrong attributions which might cause depression or determination. As a result, the researchers could offer suggestions to foster positive attitudes for compensation. Teacher training programs mostly focus on teaching methods while knowledge about learners' psychology and personality also plays an essential role. Attribution theory could be one of those areas that teachers should become familiar with as it lies at the heart of motivation. Therefore, the findings of this study and similar researches can give hints to teacher trainers and language teachers.

To further enhance our understanding of the relationship between learners' personality traits, attributional factors, and gender difference, many other studies related to the same topic can be done so that factors other than personality traits are taken into account. The same research can be done with more participants to obtain more accurate results and to generalize and project findings on to a larger population. This study used NEO-FFI to determine learners' personality traits so other personality questionnaires and scales can be used as their use might yield more significant results. Since the data of this research were collected from learners aged from 12 to 17 , it is recommended that various age groups be included in the replications to compare children and adults language learning. Some qualitative aspects such as family background can also be explored by interviewing the learners to get more accurate data for analysis. Participants of the current paper were studying at lower intermediate level. Future studies can also examine the relationship of these two variables concerning subjects' proficiency levels to see how it might effect this interaction. The same study can be replicated 
in settings other than language institutes, for example in junior high school, high school, and university. Finally, it is suggested that future studies add more variables such as culture, social class, family background, IQ, EQ, and learning styles.

\section{References}

Arnot, M., David, M., \& Weiner, G., 1999. Closing the Gender Gap: Postwar educational and social change. Cambridge: Polity Press.

Barrack, M. R., \& Mount, M. K. (1993). Autonomy as a moderator of the relationships between the Big Five personality dimensions and job performance. Journal of Applied Psychology, 78, 111-118. http://dx.doi.org/10.1037/0021-9010.78.1.111

Basow, S. A., \& Medcalf, K. L. (1988). Academic achievement and attributions among college students: Effects of gender and sex typing. Sex Roles, 19, 555-567. http://dx.doi.org/10.1007/BF00289735

Batool, S., Arif, M. H., \& Naseer Ud Din, M. (2010). Gender differences in performance attributions of mainstream and religious school students. International Journal of Academic Research, 2(6), 454-458.

Beyer, S. (1998, 1999). Gender differences in causal attributions by college students of performance on course examinations. Current Psychology: Developmental, Learning, Personality, Social, 17 (4), 346-358. http://dx.doi.org/10.1007/s12144-998-1016-5

Boyle, G. J \& Barton, K. (2008). Contribution of Cattellian personality instruments. In G. J. Boyle, G. Matthews, \& D. H. Saklofske (Eds.), The Sage handbook of personality theory and assessment, Vol. 2, (pp. 160-178). London: Sage Publications.

Brown, H. D. (2007). Principles of language learning and teaching (5th ed.). New York: Pearson Education.

Budaev, S. V. (1999). Sex differences in the Big Five personality factors: Testing an evolutionary hypothesis. Personality and Individual Differences, 26, 801-813. http://dx.doi.org/10.1016/S0191-8869(98)00179-2

Busato, V. V., Prins, F. J., Elshout, J. J., \& Hamakera, C. (1999). The relation between learning styles, the Big Five personality traits and achievement motivation in higher ducation. Personality and Individual Differences, 26, 129-140. http://dx.doi.org/10.1016/S0191-8869(98)00112-3

Cano-Garcia, F. J., Padilla-Munoz, E. M., \& Carrasco-Ortiz, M. A. (2005). Personality and contextual variables in teacher burnout. Personality and Individual Differences, 38, 929-940. http://dx.doi.org/10.1016/j.paid.2004.06.018

Cattell, H. E. P., \& Mead, A. D. (2008). The sixteen personality factor questionnaire (16PF). In G. J. Boyle, G. Matthews, \& D. H. Saklofske (Eds.), The Sage handbook of personality theory and assessment, Vol. 2, (135-159). London: Sage Publications. 


\section{$\Lambda$ Macrothink}

International Journal of Education ISSN 1948-5476

Chamorro-Premuzic, T., Furnham, A., \& Lewis, M. (2007). Personality and approaches to learning predict preference for different teaching methods. Learning and Individual Differences, 17, 241-250. http://dx.doi.org/10.1016/j.lindif.2006.12.001

Chapman, B. P., Duberstein, P. R., Sörensen, S., \& Lyness, J. M. (2007). Gender differences in Five Factor model personality traits in an elderly cohort: Extension of robust and surprising findings to an older generation. Personality and Individual Differences, 43(06), 1594-1603. http://dx.doi.org/10.1016/j.paid.2007.04.028

Chen, C., \& Zhang, L. (2011). Temperament, personality and achievement goals among Chinese adolescent students. Educational Psychology, 31 (3), 339-359. http://dx.doi.org/10.1080/01443410.2011.559310

Cortés-Suárez, G., \& Sandiford, J. R. (2008). Causal attributions for success or failure of students in College Algebra. Community College Journal of Research and Practice, 32(4), 325-346. http://dx.doi.org/10.1080/10668920701884414

Costa, Jr. P. T., \& McCrae, R. R. (2008). The revised NEO personality inventory (NEO-PI-R). In G. J. Boyle, G. Matthews, \& D. H. Saklofske (Eds.), The Sage handbook of personality theory and assessment, Vol. 2, (pp. 179-198). London: Sage Publications.

Costa, P. T., \& McCrae, R. R. (1998). Six approaches to the explication of facet-level traits: Examples from conscientiousness. European Journal of Personality, 12, 117-134. http://dx.doi.org/10.1002/(SICI)1099-0984(199803/04)12:2<117::AID-PER295>3.0.CO ;2-C

Costa, P. T., Jr., \& McCrae, R. R. (2002). Looking backward: Changes in the mean levels of personality traits from 80 to 12. In D. Cervone \& W. Mischel (Eds.), Advances in personality science (pp. 219-237). New York: Guilford Press.

Costa, P. T., Jr., \& McCrae, R. R. (2006). Age changes in personality and their origins: Comment on Roberts, Walton, and Viechtbauer (2006). Psychological Bulletin, 132, 28-30. http://dx.doi.org/10.1037/0033-2909.132.1.26

Costa, P. T., Terracciano, A., \& McCrae, R. R. (2001). Gender differences in personality traits across cultures: Robust and surprising findings. Journal of Personality and Social Psychology, 81, 322-331. http://dx.doi.org/10.1037/0022-3514.81.2.322

D'Amico, M., Baron, L. J., \& Sissons, M. E. (1995). Gender differences in attributions about microcomputer learning in elementary school. Sex Roles, 31, 353-385. http://dx.doi.org/10.1007/BF01954574

De Fruyt, F., \& Mervielde, I. (1996). Personality and interest as predictors of educational streaming and achievement. European Journal of Psychology, 10, 405-425.

Deboer, G.E. (1984). Factors related to the decision of men and women to continue taking science courses in college. Journal of Research in Science Teaching, 21, 325-329. http://dx.doi.org/10.1002/tea.3660210309 
Desprez-Bouanchaud, A., Doolaege, J., \& Ruprecht, L. (1987). Guidelines on gender-neutral language. Paris: UNESCO.

Dörnyei, Z. (2005). The psychology of the language learner individual differences in second language acquisition. New Jersey: Lawrence Elbaum Associates.

Duff, A., Boyle, E., Dunleavy, K., \& Ferguson, J. (2004). The relationship betweenpersonality, approach to learning and academic performance. Personality and Individual Differences, 36, 1907-1920. http://dx.doi.org/10.1016/j.paid.2003.08.020

Dweck, C. S. (1996). Social motivation: goals and social-cognitive processes. A comment. In J. Juvonen \& K. R. Wentzel (Eds.), Social motivation understanding children's school adjustment. Cambridge university press. http://dx.doi.org/10.1007/BF00289625

Erkut, S. (1983). Exploring sex differences in expectancy, attribution, and academic achievement. Sex Roles, 9, 217-231.

Feather, N. T. (1969). Attribution of responsibility and valence of success and failure to initial confidence and task performance. Journal of Personality and Social Psychology, 13, 129-144. http://dx.doi.org/10.1037/h0028071

Feingold, A. (1994). Gender differences in personality: A meta-analysis. Psychological Bulletin, 116, 429-456. http://dx.doi.org/10.1037/0033-2909.116.3.429

Feist, J., \& Feist, G. J. (2002). Theories of personality ( $5^{\text {th }}$ ed). New York: McGraw-Hill.

Feshbach, S., Weiner, B., \& Bohart, A. (1996). Personality $\left(4^{\text {th }}\right.$ ed). Lexington, Massachusetts: D. C. Heath and Company.

Folmer, A. S., Cole, D. A., Sigal, A. B., Benbow, L. D., Satterwhite, L. F., Swygert, K. E., \& Ciesla, J. A. (2008). Age-related changes in children's understanding of effort and ability: Implications for attribution theory and motivation. Journal of Experimental Child Psychology, 99, 114-134. http://dx.doi.org/10.1016/j.jecp.2007.09.003

Forsthuber, B., Horvath, A., \& Motiejunaite, A. (2010). Gender differences in educational outcomes: Study on the measures taken and the current situation in Europe. Brussels: Eurydice.

Garousi Farshi, M. T., Mehryar, A. H., \& Ghazi Tabatabayi, M. (2001). Application of the NEO-PI-R test and analytic evaluation of its characteristics and factorial structure among Iranian University students. Journal of Humanities, 11, 173-198.

Grant, M. B., \& Cambre, M. A. (1990). Research on teachers' characteristics in relation to a cognitive-learning based interactive videodisc system. Paper presented at the Annual Meeting of the American Educational Research Association, 16-20, Boston, MA.

Haslam, N. (2007). Introduction to personality and intelligence. London: Sage Publications.

Hyde, J.S. (2005). The gender similarities hypothesis. American Psychologist, 60(6), pp. 581-592. http://dx.doi.org/10.1037/0003-066X.60.6.581 
Karamana, N. G., Dogana, T., \& Cobana, A. E. (2010). A study to adapt the big five inventory to Turkish. Procedia Social and Behavioral Sciences 2, 2357-2359. http://dx.doi.org/10.1016/j.sbspro.2010.03.336

Kelley, H. H. (1967). Attribution theory in social psychology. In Levine, D. (Eds.), The Nebraska symposium on motivation. Lincoln: University of Nebraska Press, 192-238.

LaNoue, J. B., \& Curtis, R. C. (1985). Improving women's performance in mixed-sex situations by effort attributions. Psychology of Women Quarterly, 9, 337-356. http://dx.doi.org/10.1111/j.1471-6402.1985.tb00885.x

Lee, S., \& Klein, H. J. (2002). Relationships between conscientiousness, self efficacy, selfdeception, and learning over time. Journal of Applied Psychology, 87(6), 1175-1182. http://dx.doi.org/10.1037/0021-9010.87.6.1175

Lim, H. (2007). Effects of attributions and task values on foreign language use anxiety. Journal of Education and Human Development, 1(2), 1-20.

Manusov, V., \& Spitzberg, B. H. (2008). Attributes of attribution theory: Finding good cause in the search for theory. In D. O. Braithwaite \& L. A. Baxter (Eds.), Engaging theories in interpersonal communication (pp. 37-49). Thousand Oaks, CA: Sage Publications.

Martin, B. A., Kovac, M. L., \& Hryshko, A. (1989). Causal attributions and anticipated work performance. Journal of Social Behavior and Personality, 4, 491-502.

Mayer, J. D. (2005). A tale of two visions: Can a new view of personality help integrate psychology. American Psychological Association, 60(4), 294-307.

McCrae, R. R., \& Costa, P. T., Jr. (2003). Personality in adulthood: A Five-Factor Theory $\begin{array}{llll}\text { perspective (2nd. } & \text { ed.). New } & \text { York: Guilford Press. }\end{array}$ http://dx.doi.org/10.4324/9780203428412

McCrae, R. R., Terracciano, A., \& 78 Members of the Personality Profiles of Cultures Project (2005). Universal features of personality traits from the observer's perspective: Data from 50 cultures. Journal of Personality and Social Psychology, 88, 547-561. http://dx.doi.org/10.1037/0022-3514.88.3.547

Meece, J. L., Glienke, B. B.Samantha, \& Burg, S. (2006). Gender and motivation. Journal of School Psychology 44, 351-373. http://dx.doi.org/10.1016/j.jsp.2006.04.004

Meehan, A. M., \& Overton, W. F. (1986). Gender differences in expectancies for success and performance on Piagetian spatial tasks. Merrill-Palmer Quarterly, 32, 427-441.

Müller, F. H., Palekčić, M., Beck, M., \& Wanninger, S. (2006). Personality, motives and learning environment as predictors of self-determined learning motivation. Review of Psychology, 13(2), 75-86.

Mynatt, C. R., \& Doherty, M. E. (2002). Understanding human behavior ( $2^{\text {nd }}$ ed). Boston: Allyn \& Bacon. 
Parsons, J. E., Kaczala, C. M., \& Meece, J. L. (1982). Socialization of achievement attitudes and beliefs: Classroom influences. Child Development, 53, 322-339. http://dx.doi.org/10.2307/1128974

Parsons, J. E., Meece, J. L., Adler, T. F., \& Kaczala, C. M. (1982). Sex differences in attributions and learned helplessness. Sex Roles, 8, 421-432. http://dx.doi.org/10.1007/BF00287281

Parsons, J., Adler, T. F., \& Kaczala, C. M. (1984). Socialization of achievement attitudes and beliefs: Parental influences. Child Development, 53, 322-339. http://dx.doi.org/10.2307/1128974

Pasquella, M. H., Mednick, M. T. S., \& Murray, S. R. (1981). Causal attributions for achievement outcomes: Sex-role identity, sex and outcome comparisons. Psychology of Women Quarterly, 5, 586-589. http://dx.doi.org/10.1111/j.1471-6402.1981.tb00596.x

Peacock, M. (2010). Attribution and learning English as a foreign language. ELT Journal, 64, 184-193. http://dx.doi.org/10.1093/elt/ccp031

Pishghadam, R., \& Modarresi, G. (2008). The construct validation and application of questionnaire of attribution theory for foreign language learners. Iranian Journal of Language Studies, 2(3), 299-324.

Pishghadam, R., \& Motakef, R. (2011). Attributional patterns with respect to major and attendance in private language schools: A case of EFL context. Theory and Practice in Language Studies, 1(7), 888-894. http://dx.doi.org/10.4304/tpls.1.7.888-894

Pishghadam, R., \& Zabihi, R. (2011). Foreign language attributions and achievement in foreign language classes. International Journal of Linguistics, 3(1), 1-11.

Postlethwaite, K., \& Haggarty, L. (2001). Towards the improvement of learning in secondary school: students' views, their links to theories of motivation and to issues of under- and over-achievement. Research Papers in Education, 17 (2), 185-209. http://dx.doi.org/10.1080/02671520210122937

Schmitt, D. P., Realo, A., Voracek, M., \& Allik, J. (2008). Why can't a man be more like a woman? Sex differences in Big Five. Personality traits across 55 cultures. Journal of $\begin{array}{llll}\text { Personality and Social Pychology, } & \text { 94(1), }\end{array}$ http://dx.doi.org/10.1037/0022-3514.94.1.168

Takahashi, S. (2003). The role of attribution for success and failure in second language reading by Japanese university students. Unpublished doctoral dissertation. Temple University, Michigan. (UMI No. 3097731).

Travis, C. B., Phillippi, R. H., \& Henley, T. B. (1991). Gender and causal attributions for mastery, personal, and interpersonal events. Psychology of Women Quarterly, 15, 233-249. http://dx.doi.org/10.1111/j.1471-6402.1991.tb00794.x 
Viaene, N. (1979). Sex differences in explanations of success and failure. In O. A. Hartnett, G. Boden, \& M. Fuller (Eds.), Sex-role stereotyping. New York: Travistock.

Watson, D., Clark, L. A., \& Harkness, A. R. (1994). Structures of personality and their relevance to psychopathology. Journal of Abnormal Psychology, 108, 18-31. http://dx.doi.org/10.1037/0021-843X.103.1.18

Weiner, B. (1974). Motivational psychology and educational research. Educational Psychologist, 11 (2), 96-101. http://dx.doi.org/10.1080/00461527409529130

Weiner, B. (1979). A theory of motivation for some classroom experiences. Journal of Psychology, 71, 3-25.

Weiner, B. (1986). An attributional theory of motivation and emotion. New York: Springer-Verlag. http://dx.doi.org/10.1007/978-1-4612-4948-1

Whalen, T., \& Gates, C. (2007). A psychological profile of defender personality traits. Journal of Computers, 2, 84-93. http://dx.doi.org/10.4304/jcp.2.2.84-93

Williams, M., \& Burden, R. L. (1997). Psychology for language teachers: A social constructivist approach. Cambridge: Cambridge University Press.

Williams, M., Burden, R., \& Al-Baharna, S. (2001). Making sense of success and failure: The role of the individual in motivation theory. In Z. Dörnyei, \& R. Schmidt (Eds.), Motivation and second language acquisition (pp. 171-184). Honolulu: University of Hawaii, Second Language Teaching and Curriculum Center.

Williams, M., Burden, R., Poulet, G., \& Maun, I. (2004). Learners' perceptions of their success and failure s in foreign language learning. Language Learning Journal, 30, 19-29. http://dx.doi.org/10.1080/09571730485200191

Wu, J. (2011). An investigation and analysis of attribution preference and gender difference of non-English majors' English learning - based on investigation of non-English majors in Tianjin Polytechnic University. Journal of Language Teaching and Research, 2(2), 332-337. http://dx.doi.org/10.4304/j1tr.2.2.332-337

Zhang, L. (2003). Does the Big Five predict learning approaches? Personality and Individual Differences, 34, 1431-1446. http://dx.doi.org/10.1016/S0191-8869(02)00125-3

\section{Copyright Disclaimer}

Copyright reserved by the author(s).

This article is an open-access article distributed under the terms and conditions of the Creative Commons Attribution license (http://creativecommons.org/licenses/by/3.0/). 